\title{
Advanced CFD Analysis of an Air-cooled PEM Fuel Cell Stack Predicting the Loss of Performance with Time ${ }^{\boldsymbol{\Lambda}}$
}

\author{
C. Fink ${ }^{1 *}$, L. Karpenko-Jereb ${ }^{2}$, S. Ashton ${ }^{3}$ \\ ' AVL List GmbH, Hans-List-Platz 1, 8020 Graz, Austria \\ ${ }^{2}$ Graz University of Technology, Stremayrgasse 9/I, 8010 Graz, Austria \\ 3 Intelligent Energy, Holywell Park, LE1 1 3GB Loughborough, UK
}

Received October 21, 2915; accepted April 19, 2016; published online April 29, 2016

\begin{abstract}
The PEM fuel cell simulation package developed by AVL List $\mathrm{GmbH}$ is coupled with a semi-empirical degradation model describing the dependency of material parameters on operating conditions. The CFD model calculates the 3D distributions of electronic/ionic potentials, velocity, pressure, phase volume fractions, gas species mass fractions, and temperature in all solids and fluids of PEM fuel cell stacks, as well as water concentration and hydraulic pressure in the membrane. The degradation model modifies membrane and catalyst layer parameters according to local operating conditions and given operating time during the simulation run-time.
\end{abstract}

Calculated distributions of current density and temperature are compared to experimental data of an air-cooled PEM fuel cell stack obtained with segmented measurement plates. For the validation of the degradation model, calculated current density decay vs. operating time are compared to throughlife polarization measurements. The good agreement between measurement and simulation demonstrates the ability of the model to predict the complex physical phenomena taking place in PEM fuel cells with high accuracy.

Keywords: Air Cooling, CFD Simulation, Degradation Model, Electrochemistry, Fuel Cells, Heat Transfer

\section{Introduction}

The transport processes taking place in polymer electrolyte membrane (PEM) fuel cells as well as their interactions are very complex. 3D computational fluid dynamics (CFD) simulation in combination with electrochemical models helps to understand the physical behavior of PEM fuel cells and, thus, reduce development time and costs dramatically. One of the first efforts using CFD simulation to study PEM fuel cells appeared fifteen years ago [1] and was focused on the optimization of flow-field design. Since that time, CFD simulation tools have been extensively developed and applied to investigate and design fuel cell systems. The investigations can be divided into four main categories:

- Paper presented at the $5^{\text {th }}$ EUROPEAN PEFC \& $\mathrm{H}_{2}$ FORUM (EFCF2015), June 30 - July 3, 2015 held in Lucerne, Switzerland. Organized by the European Fuel Cells Forum www.efcf.com (i) Optimization and design of the fuel cell components such as membrane electrode assembly (MEA), gas diffusion layer (GDL), bipolar plates with flow field, or cooling channels [2-6];

(ii) Study of the influence of material properties on the fuel cell performance [7-10];

(iii) Investigation of the effects of operating parameters such as gas flow rates, stoichiometries, relative humidity, temperature and pressure along with transient operation or voltage cycling [11-13];

(iv) Analysis of the inner phenomena such as water droplet emergence, transport of gas species, electric charge and heat as well as electrochemical reactions [14,15].

Using CFD simulation, critical regions in fuel cells and critical operating conditions can be identified and, furthermore, optimized. Moreover, the effects of material parameters can be

[*] Corresponding author, clemens.fink@avl.com 
investigated allowing an optimal compromise between material costs and performance to be found.

A current challenge in the CFD modeling of the PEM fuel cell is the simulation of degradation phenomena in the materials and the prediction of the cell performance during the lifetime of the fuel cell. CFD simulation has been used to investigate the displacement, mechanical deformation, and stresses inside the fuel cell occurring during the cell operation due to the changes of temperature and relative humidity [16]. Since 2002, Franco et al. [17] have been developing a transient, multi-scale and multi-physics single cell model. In 2007, this model was applied to analyze the effect of catalyst layer aging on the cell behavior [18]. Here, density functional theory and molecular dynamics were used to calculate the kinetic parameters of the electrochemical reaction, the Monte Carlo method was applied to simulate properties of the platinum catalyst in the degraded state, and the efficiency of the fuel cell was predicted using CFD. The approach was also applied to study the impact of CO contamination on the electrochemical activity of catalysts and cell degradation $[19,20]$. Robin et al. [21] developed the multi-scale model further and used it in order to compare the influence of nominal operating conditions and power cycling on the cell performance decay. Ozden and Tari [22] studied changes in the performance of degraded PEM fuel cells by modifying the material parameters affected by degradation. The modified parameters were bipolar plate contact resistance, the membrane equivalent weight, the porosity and viscous resistance of the catalyst layer and GDL. The calculated polarization curves of healthy and degraded cells were found to be in good agreement with experimental data. It was pointed out, that the bipolar plate conductivity affected the fuel cell performance more than other studied material properties. The cited degradation models [18, 21, 22], however, have the two key shortcomings in common: (i) they do not consider changes of geometry parameters, such as membrane or GDL thickness, and (ii) they do not take into account a dependence of the material degradation rates on local operating conditions in the fuel cell.

In the present work, a semi-empirical degradation model describing the dependency of geometry and material parameters on operating conditions is implemented into a commercial CFD software package [23]. The overall model enables the prediction of the fuel cell performance as a function of operating time, and can be applied to simulate complete PEM fuel cell stacks. Moreover, the model considers the influence of local operating conditions such as relative humidity, temperature, pressure and electric potential on the degradation rates of the polymer electrolyte membrane and catalyst layer. It enables the analysis of non-uniform changes in material properties, their functionality and effect on the cell behavior. In section 2 both basic and degradation models are described while section 3 contains simulation setup, experimental validation, and interpretation of 3D simulation results.

\section{Model Description}

\subsection{Basic Model}

The basic PEM fuel cell model [23] calculates the 3D transport processes of electrons, ions, gas species, gas mixture, liquid water, and heat in all fuel cell domains as well as electrochemical reactions and interphase heat and mass transfer (see Figure 1). The model is based on the following assumptions:

(i) Volume averaging approach for porous media: The solid structure of the porous GDL and microporous layer (MPL) is not locally resolved, but, instead, the porous medium is divided into a number of representative elementary volumes (REVs) [24], i.e. the smallest volume that represents a meaningful statistical average of local properties. This homogenization technique leads to a characterization of the porous medium by average properties such as porosity, tortuosity, or permeability.

(ii) For the interphase mass, momentum, and heat transfer between gas and liquid, spherical droplets are assumed both in the flow channel and in the GDL.

(iii) For the heat transfer between porous solid and fluid, the porous medium is assumed to consist of spherical solid particles.

(iv) The catalyst layer is modeled as a $2 \mathrm{D}$ interface, i.e. it is not meshed. Consequently, the electrochemical reaction is assumed to occur at the interface membrane/GDL (or membrane/MPL). Hence, the reaction current density is used as an (inner) boundary condition for the electronic charge conservation equation in the GDL (or MPL) and for the ionic charge conservation equation in the membrane.

(v) The model is suited for stationary fuel cell operation, i.e. transient effects are not considered;

(vi) The gas phase is ideal;

(vii) The influence of gravity is neglected.

\subsubsection{Catalyst Layer}

The electrochemical half-cell reactions (see Figure 1) are described with the Butler-Volmer equation [23]:

$i_{r}=i_{0}\left[\exp \left(\frac{2 k_{a} F}{R T_{s}} \eta\right)-\exp \left(-\frac{2 k_{c} F}{R T_{s}} \eta\right)\right]$

with the activation overpotential

$\eta=\phi_{\text {ele }}-\phi_{\text {ion }}-\phi_{o c}$

and the exchange current density

$$
\begin{aligned}
i_{0}= & i_{0, \text { ref }}\left(\frac{p_{\mathrm{O}_{2}}}{p_{\text {ref }}}\right)^{b_{\mathrm{O}_{2}}}\left(\frac{p_{\mathrm{H}_{2}}}{p_{\text {ref }}}\right)^{b_{\mathrm{H}_{2}}}\left(\frac{p_{\mathrm{H}_{2} \mathrm{O}}}{p_{\text {ref }}}\right)^{b_{\mathrm{H}_{2} \mathrm{O}}} \\
& \frac{\alpha_{g}}{\varepsilon} \exp \left[-\frac{E_{a, i_{0}}}{R}\left(\frac{1}{T_{S}}-\frac{1}{T_{r e f, i_{0}}}\right)\right]
\end{aligned}
$$




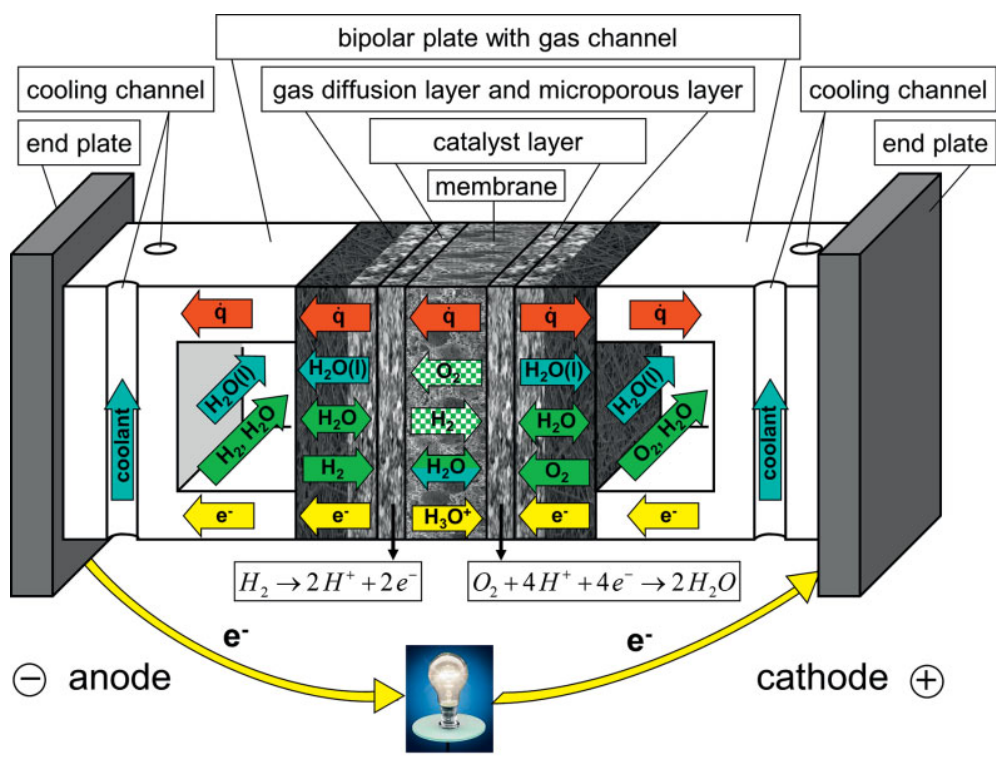

Gas species $\square$ Liquid $\square$ Heat $\square$ Electrons \& ions

Fig. 1 Working principle of a PEM fuel cell: transport quantities and reactions [23].

The reference pressure $p_{\text {ref }}$ is $101,325 \mathrm{~Pa} . \phi_{\text {ele }}$ and $\phi_{\text {ion }}$ in Eq. (2) are electronic and ionic potential in the catalyst layer, respectively. The open circuit potential $\phi_{o c}$ is calculated with the Nernst equation according to

$\phi_{o c, c a t}=1.498-9 \times 10^{-4} T_{g, c a t}+\frac{R T_{g, c a t}}{4 F} \ln \frac{p_{\mathrm{O}_{2}, \text { cat }} p_{\text {ref }}}{p_{\mathrm{H}_{2} \mathrm{O}, \mathrm{cat}}^{2}}$

at the cathode and

$\phi_{\text {oc,ano }}=\frac{R T_{g, \text { ano }}}{2 \mathrm{~F}} \ln \frac{p_{\text {ref }}}{p_{\mathrm{H}_{2}, \text { ano }}}$

at the anode. The parameters $i_{0, r e f}, k_{c}, k_{a}, b_{\mathrm{H}_{2}}, b_{\mathrm{H}_{2} \mathrm{O}}$, and $b_{\mathrm{O}_{2}}$ can be used as fitting parameters for the activation overpotential. The existence of fitting parameters in the model is a necessary evil due to the volume averaging method of the porous media and the treatment of the catalyst layer as interface.

\subsubsection{Membrane}

In the membrane hydrogen can be found in three groups:

(i) $\mathrm{H}_{2} \mathrm{O}$ : free water;

(ii) $\mathrm{H}_{3} \mathrm{O}^{+}$: hydronium ions;

(iii) $\mathrm{SO}_{3}{ }^{-} \mathrm{H}^{+}$: hydrogen protons bound to the fixed charged acid groups.

An electrochemical equilibrium between these groups is assumed. Free water and hydronium ions are moving across the membrane. Therefore, proper transport equations for these quantities have to be solved inside the membrane. The quantities of interest in this context are the water concentration $C_{w}$ and the ionic potential $\phi_{i o n}$. The water concentration $C_{w}$ is the result of the following water transport mechanisms: (i) Diffusion: The driving force is the water concentration difference between cathode and anode catalyst layer.

(ii) Electro-osmotic drag: Hydrogen protons drag water molecules from the anode to the cathode.

(iii) Convection: The driving force for this transport mechanism is the (hydraulic) pressure difference between the electrodes. Water is pushed from the electrode with higher hydraulic pressure across the membrane towards the other electrode.

The ionic potential results from the ionic charge conservation in the membrane. Beside water and ions, heat is transported across the membrane. The nondimensional water concentration $C_{w}$, i.e. water concentration normalized by the sulfonic acid group concentration $a$, is solved from the water mass balance

$\nabla \cdot \overrightarrow{\dot{n}}_{w}=0$

in which the membrane water flux is calculated with the Nernst-Planck equation according to

$$
\overrightarrow{\dot{n}}_{w}=-a D_{w} \nabla C_{w}+C_{d r a g} \frac{\vec{i}_{i o n}}{F}-a \varepsilon_{m e m} C_{w} \frac{K_{p}}{\mu_{w}} \nabla p_{l}
$$

The three terms in Eq. (7) can be attributed to the three water transport effects, i.e. (from left to right) diffusion, electro-osmotic drag, and convection. Water diffusion coefficient $D_{w}$ and osmotic drag coefficient $C_{d r a g}$ depend on water concentration and temperature as follows:

$D_{w}=D_{w, r e f} C_{w} \exp \left[-\frac{E_{a, D}}{R}\left(\frac{1}{T}-\frac{1}{T_{r e f, D}}\right)\right]$

$C_{\text {drag }}=C_{\text {drag, ref }} C_{w} \exp \left[-\frac{E_{a, C_{\text {drag }}}}{R}\left(\frac{1}{T}-\frac{1}{T_{\text {ref }, C_{\text {drag }}}}\right)\right]$

The boundary conditions for Eq. (6) are the water fluxes in the catalyst layers which are calculated as follows:

$\overrightarrow{\dot{n}}_{w, c a t}^{f} \cdot \vec{n}^{f}=\left(C_{w, c a t}^{*}-C_{w, c a t}^{f}\right) \gamma_{w, c a t} a-\frac{i_{r, c a t}}{2 F}$

$\overrightarrow{\dot{n}}_{w, \text { ano }}^{f} \cdot \vec{n}^{f}=\left(C_{w, \text { ano }}^{*}-C_{w, \text { ano }}^{f}\right) \gamma_{w, \text { ano }} a$

The superscript $f$ denotes the interface membrane/catalyst layer. $\gamma_{w}$ is a mass transfer coefficient [23] and $C_{w}^{*}$, the membrane equilibrium sorption value of the water concentration, is a function of the relative humidity and the temperature. The following water sorption isotherm is applied [25]:

$$
C_{w}^{*}=\left(1.55+13.71 \varphi_{w}-24.37 \varphi_{w}^{2}+21.87 \varphi_{w}^{3}\right) f\left(C_{w, \max }, \varphi_{w}\right)
$$


Eq. (12) includes Schroeder's paradox, i.e. the sudden increase of the water concentration at the interface membrane/ catalyst layer under super-saturated gas conditions and the temperature effect on the membrane water sorption via the maximum membrane water concentration

$C_{w, \max }=0.138 T-28.31$

The hydraulic pressure $p_{1}$ in Eq. (7) is assumed to have a linear distribution in the membrane, i.e.

$\nabla \cdot \nabla p_{l}=0$

The ionic potential $\phi_{\text {ion }}$ is calculated from the ionic charge conservation according to

$\nabla \cdot \vec{i}_{\text {ion }}=0$

with the ionic current density

$\vec{i}_{\text {ion }}=-\sigma_{\text {ion }} \nabla \phi_{\text {ion }}$

The ionic conductivity depends on water concentration and temperature as follows:

$\sigma_{i o n}=\sigma_{i o n, r e f} C_{w} \exp \left[-\frac{E_{a, \sigma}}{R}\left(\frac{1}{T}-\frac{1}{T_{r e f, \sigma}}\right)\right]$

At the interface between membrane and catalyst layer the reaction current density (Eq. (1)) is used as a boundary condition for Eq. (15), i.e. at this interface ionic and reaction current density are equal:

$\vec{i}_{\text {ion }}^{f} \cdot \vec{n}^{f}=i_{r}$

The local temperature in the membrane is calculated from the energy equation under the assumption of pure heat conduction and with an ohmic heat source caused by the ion transport:

$\nabla \cdot\left(-\lambda_{\text {mem }} \nabla T\right)=-\vec{i}_{\text {ion }} \cdot \nabla \phi_{\text {ion }}$

\subsubsection{Flow Channel and Gas Diffusion Layer}

In the flow channels and gas diffusion layers, the distributions of fluid velocities, fluid volume fractions, pressure, gas species mass fractions, and fluid temperatures are calculated. In the gas diffusion layers, additionally, the solid temperature and the electronic potential are solved. Below, the respective transport equations are mentioned. A detailed description of the source terms would go beyond the scope of the present work and can be found in [26].

(i) Velocities of phase $p$ from momentum equations:

$\nabla \cdot\left(\alpha_{p} \rho_{p} \vec{u}_{p} \vec{u}_{p}\right)=-\alpha_{p} \nabla p+\nabla \cdot\left(\alpha_{p} \tau_{p}\right)+\vec{S}_{p}+\vec{S}_{p c, p}$ for $p=g, l$ (ii) Volume fractions of phase $p$ from phase mass balances:

$\nabla \cdot\left(\alpha_{p} \rho_{p} \vec{u}_{p}\right)=\dot{M}_{p c, p}$ for $p=g, l$

(iii) Pressure from continuity equation (together with momentum equations):

$\nabla \cdot\left(\alpha_{g} \rho_{g} \vec{u}_{g}+\alpha_{l} \rho_{l} \vec{u}_{l}\right)=0$

(iv) Mass fractions of gas species $i$ from species mass balances:

$\nabla \cdot\left(\alpha_{g} \rho_{g} y_{i} \vec{u}_{g}+\alpha_{g} \vec{j}_{i}\right)=\dot{M}_{p c, i}$ for $i=\mathrm{O}_{2}, N_{2}, H_{2}, H_{2} \mathrm{O}$

(v) Temperatures of phase $p$ from energy equations:

$$
\begin{aligned}
\nabla \cdot\left(\alpha_{p} \rho_{p} H_{p} \vec{u}_{p}-\alpha_{p} \lambda_{p} \nabla T_{p}\right)= & \nabla \cdot\left(\alpha_{p} \tau_{p} \cdot \vec{u}_{p}\right)+\dot{Q}_{p}+\dot{Q}_{D, p} \\
& +\dot{Q}_{p c, p} \text { for } p=g, l
\end{aligned}
$$

$\nabla \cdot\left(-\alpha_{s} \lambda_{s} \nabla T_{s}\right)=\dot{Q}_{s}-\vec{i}_{\text {ele }} \cdot \nabla \phi_{\text {ele }}$

(vi) Electronic potential of solid phase from charge conservation equation:

$\nabla \cdot\left(\vec{i}_{\text {ele }}\right)=0$

with

$\vec{i}_{\text {ele }}=-\alpha_{s} \sigma_{\text {ele }} \nabla \phi_{\text {ele }}$

In the catalyst layers, mass, heat, and current sources for the GDL (or MPL) arise due to the electrochemical reactions and the transport processes across the membrane. These sources cannot be found in the transport equations above, since they are surface rather than volume sources and, hence, are treated as internal boundary conditions. The gas species mass sources for Eq. (23) read

$\overrightarrow{\dot{m}}_{\mathrm{O}_{2}, \text { cat }}^{f} \cdot \vec{n}^{f}=-\frac{i_{r, c a t} M_{\mathrm{O}_{2}}}{4 F}$

$\overrightarrow{\dot{m}}_{\mathrm{H}_{2} \mathrm{O}, \mathrm{cat}} \cdot \vec{n}^{f}=\frac{i_{r, c a t} M_{\mathrm{H}_{2} \mathrm{O}}}{2 \mathrm{~F}}+\mathrm{M}_{\mathrm{H}_{2} \mathrm{O}}\left(\overrightarrow{\dot{\vec{n}}}_{w, \text { cat }} \cdot \vec{n}^{f}\right)$

$\overrightarrow{\dot{m}}_{\mathrm{H}_{2}, a n o} \cdot \vec{n}^{f}=\frac{i_{r, a n o} M_{\mathrm{H}_{2}}}{2 \mathrm{~F}}$

$\overrightarrow{\dot{m}}_{\mathrm{H}_{2} \mathrm{O}, \text { ano }} \cdot \vec{n}^{f}=M_{\mathrm{H}_{2} \mathrm{O}}\left(\overrightarrow{\dot{\vec{n}}}_{\text {w,ano }}^{f} \cdot \vec{n}^{f}\right)$ 
The sum over all gas species mass sources yields the gas phase mass sources for Eqs. (21) and (22):

$\overrightarrow{\dot{m}}_{c a t}^{f} \cdot \vec{n}^{f}=-\frac{i_{r, c a t} M_{\mathrm{O}_{2}}}{4 F}+\frac{i_{r, c a t} M_{\mathrm{H}_{2} \mathrm{O}}}{2 F}+M_{\mathrm{H}_{2} \mathrm{O}}\left(\overrightarrow{\vec{n}}_{w, \text { cat }}^{f} \cdot \vec{n}^{f}\right)$

$\overrightarrow{\dot{m}}_{\text {ano }}^{f} \cdot \vec{n}^{f}=\frac{i_{r, a n o} M_{H_{2}}}{2 F}+M_{H_{2} O}\left(\overrightarrow{\dot{n}}_{w, a n o} \cdot \vec{n}^{f}\right)$

The current source for Eq. (26) reads

$\vec{i}_{\text {ele }}^{f} \cdot \vec{n}^{f}=i_{r}$

and the heat source for Eq. (25) reads

$\dot{q}^{f}=i_{r}\left(\eta+T_{g} \frac{\partial \phi_{o c}}{\partial T}\right)$

with

$\left(\frac{\partial \phi_{o c}}{\partial T}\right)_{c a t}=-9 \times 10^{-4}+\frac{R}{4 F} \ln \frac{p_{\mathrm{O}_{2}, c a t} p_{r e f}}{p_{\mathrm{H}_{2} \mathrm{O}, \mathrm{cat}}^{2}}$

$\left(\frac{\partial \phi_{o c}}{\partial T}\right)_{\text {ano }}=\frac{R}{2 F} \ln \frac{p_{\text {ref }}}{p_{H_{2}, \text { ano }}}$

\subsubsection{Bipolar Plate}

In the bipolar plate only heat and electron conduction takes place. Solid temperature and electronic potential are obtained from the following equations:

$\nabla \cdot\left(-\lambda_{s} \nabla T_{s}\right)=\sigma_{\text {ele }} \cdot\left(\nabla \phi_{\text {ele }}\right)^{2}$

$\nabla \cdot\left(-\sigma_{\text {ele }} \nabla \phi_{\text {ele }}\right)=0$

\subsection{Degradation Model}

The basic model is coupled with a semi-empirical degradation model. The purpose of the degradation model is to describe geometry and material parameter changes due to degradation of the membrane and the catalyst layers. As an additional independent variable the fuel cell operating time is introduced. The calculated degradation rate of the polymer electrolyte membrane depends on local physical conditions such as temperature, humidity, pressure, and voltage. The calculation of the membrane degradation rate is based on an assumption that the changes in the membrane properties are caused by interaction of the membrane polymer chains with hydroxyl radicals. Wong et al. [27] suggested the following degradation mechanisms of the perfluorinated membrane based on the experimental data published in [28, 29]: (i) Degradation of the main chains of the perfluorinated membrane:

$\mathrm{R}_{p}-\mathrm{CF}_{2} \mathrm{COOH}+\mathrm{OH} \cdot \rightarrow \mathrm{R}_{p}-\mathrm{CF}_{2} \cdot+\mathrm{CO}_{2}+\mathrm{H}_{2} \mathrm{O}$

$R_{p}-\mathrm{CF}_{2} \cdot+\mathrm{OH} \cdot \rightarrow \mathrm{R}_{p}-\mathrm{CF}_{2} \mathrm{OH} \rightarrow \mathrm{R}_{p}-\mathrm{COF}+\mathrm{HF}$

$R_{p}-\mathrm{COF}+\mathrm{H}_{2} \mathrm{O} \rightarrow \mathrm{R}_{p}-\mathrm{COOH}+\mathrm{HF}$

(ii) Degradation of the side chains of the membrane:

$$
\begin{aligned}
& R_{p}-\mathrm{OCF}_{2} \mathrm{CF}\left(\mathrm{CF}_{3}\right) \mathrm{O}\left(\mathrm{CF}_{2}\right)_{2} \mathrm{SO}_{3}^{-}+\mathrm{OH} \cdot \rightarrow R_{p}-\mathrm{OH} \\
& \quad+\mathrm{OCF}_{2} \mathrm{CF}\left(\mathrm{CF}_{3}\right) \mathrm{O}\left(\mathrm{CF}_{2}\right)_{2} \mathrm{SO}_{3}^{-}
\end{aligned}
$$

$R_{p}-\mathrm{OCF}_{2} \mathrm{CF}\left(\mathrm{CF}_{3}\right) \mathrm{O}\left(\mathrm{CF}_{2}\right)_{2} \mathrm{SO}_{3}^{-}+\mathrm{OH} \cdot \rightarrow \mathrm{R}_{p}-$

$\mathrm{OCF}_{2} \mathrm{CF}\left(\mathrm{CF}_{3}\right) \mathrm{O} \cdot+\mathrm{HO}\left(\mathrm{CF}_{2}\right)_{2} \mathrm{SO}_{3}^{-}$

$$
\begin{aligned}
R_{p} & -\mathrm{OCF}_{2} \mathrm{CF}\left(\mathrm{CF}_{3}\right) \mathrm{O} \cdot+\mathrm{H}_{2} \mathrm{O}+\mathrm{OH} \cdot \rightarrow \mathrm{R}_{p} \\
& -\left(\mathrm{CF}_{2}\right)_{n} \mathrm{COOH}+\mathrm{HF}
\end{aligned}
$$

Both degradation mechanisms result in a decrease in the equivalent weight of the polymer. By losing the parts of the polymer, the membrane becomes thinner during the degradation as observed in [30]. The second mechanism leads to splitting of parts of the side chains containing the acid groups, which are responsible for the membrane functionality such as ionic conductivity, proton and water transport. Since the concentration of the hydroxyl radicals correlates with the oxygen crossover flux through the membrane [30], we assume the degradation rates of the membrane properties to be proportional to the oxygen crossover:

$\frac{\dot{r}_{\psi}}{\dot{r}_{r e f, \psi}}=\frac{J_{O_{2}}}{J_{O_{2}, r e f}}$

Eq. (46) can be used in order to calculate membrane degradation rates at arbitrary operating conditions in case a degradation rate is known at a certain reference operating condition. The development and approach of the membrane degradation model are described in [31]. For the operating conditions of interest, i.e. difference between anode and cathode pressure between $0 \mathrm{~Pa}$ and 50,000 $\mathrm{Pa}$ and cell voltage between $0.4 \mathrm{~V}$ and $1 \mathrm{~V}$, the membrane degradation rates are calculated as follows:

$$
\begin{aligned}
& \dot{r}_{\psi}=\frac{\dot{r}_{\text {ref }, \psi}}{J_{O_{2}, \text { ref }}} \\
& {\left[-6.97 \times 10^{4}+180 T+36 \varphi_{w}+\frac{1.09 \times 10^{5}}{\ln L_{\text {mem }}^{t=0}}+0.06\left(p_{\text {cat }}-p_{\text {ano }}\right)\right]}
\end{aligned}
$$$$
(1.12 V-0.06)
$$ 
where $\psi$ is one out of membrane properties: membrane thickness $L_{m e m}$, ionic conductivity $\sigma_{i o n}$, or acid group concentration a. The derivation of Eq. (47) [32] is based on the experimental data from [33]. The membrane parameters $\psi$ at an operating time $t$ are calculated via

$\psi^{t}=\psi^{t=0}\left(1-\dot{r}_{\psi} t\right)$ for $\psi=L_{m e m}, \sigma_{i o n}, a$

The degradation of the cathode catalyst layer is modeled using the experimental data reported in $[34,35]$ and taking into account the operating conditions of the tested stack. The reference exchange current density at the cathode at time $t$ is calculated from the initial value according to

$$
\begin{aligned}
& i_{0, \text { ref,cat }}^{t}=i_{0, \text { ref,cat }}^{t=0} \\
& \left\{\begin{array}{cc}
1-1.4 \times 10^{-3} t+1.3 \times 10^{-6} t^{2}-5 \times 10^{-10} t^{3}+6.6 \times 10^{-14} t^{4} \\
0.4-2.8 \times 10^{-5} t
\end{array}\right\} \\
& \text { for }\left\{\begin{array}{l}
t \leq 1,564 \mathrm{~h} \\
t>1,564 \mathrm{~h}
\end{array}\right.
\end{aligned}
$$

The modified geometry and material parameters are applied to the basic model in order to calculate the stationary fuel cell performance for a fixed operating time.

\section{Results and Discussion}

Simulation results of an air-cooled PEM fuel cell stack are compared to measurements by Intelligent Energy. First, the simulation is adjusted to a measured reference polarization curve using fitting parameters from the Butler-Volmer Eq. (1). Then, the calculated current density and temperature distributions are compared to values measured using $\mathrm{S}^{++}$-sensor plates [36]. For the validation of the degradation model, the model is adjusted to a measured voltage decay for a fixed current density and, after that, calculated current density decay vs. operating time are compared to through-life polarization measurements. Additionally, 3D simulation results are analyzed in detail.

\subsection{Simulation Setup}

The computational mesh consisting of 9,114,628 computational cells is shown in Figure 2. The stack has an open cathode and no external humidification. Ambient air, provided by a fan, is used as both oxidant and coolant. There are two cathodic GDLs and one anodic GDL. The GDLs touching the MEA have additional MPLs which are considered as additional computational domains. Hydrogen is forced to flow around the anodic GDL, thus enforcing lateral $\mathrm{H}_{2}$ diffusion across GDL and MPL to the catalyst layer. In Table 1 the material and transport parameters are listed. All parameters except the membrane parameters are determined from measurements at a compression of $148 \mathrm{~N} \mathrm{~cm}^{-2}$. The membrane parameters are taken from $[25,26]$. The GDL/ MPL conductivities and permeabilities from Table 1 are through-plane values. The in-plane values are assumed to be tenfold (for thermal conductivity fivefold) of the throughplane values. The GDL/MPL tortuosities are calculated via the Bruggeman relation with the gas volume fraction according to $\tau=\alpha_{g}{ }^{-0.5}$. Boundary and operating conditions are listed in Table 2. Table 3 contains the kinetic parameters from the Butler-Volmer Eq. (1). The values marked with an asterisk are used as fitting parameters. They are obtained from fitting the calculated average current densities to a measured reference polarization curve (see Figure 3). The fitting parameters for the membrane degradation model are the reference degradation rates $\dot{r}_{r e f, \psi}$ from Eq. (47). Their values are obtained from fitting the model to a measured voltage decay at a current density of $10,000 \mathrm{~A} \mathrm{~m}^{-2}$ :

$\dot{r}_{\text {ref }, L_{\text {mem }}}=1.35 \times 10^{-5} \mathrm{~h}^{-1}, \dot{r}_{\text {ref }, \sigma_{\text {ion }}}=\dot{r}_{\text {ref }, a}=2.7 \times 10^{-5} \mathrm{~h}^{-1}$

The value of the reference oxygen crossover rate is

$J_{O_{2}, r e f}=4,500 \mathrm{~mol} \mathrm{~m}^{-2} \mathrm{~s}^{-1}$

The computational time for one stationary operating point is about $26 \mathrm{~h}$ using 64 CPUs on quad-core Intel Xeon E5620 processors with a frequency of $2.4 \mathrm{GHz}$.

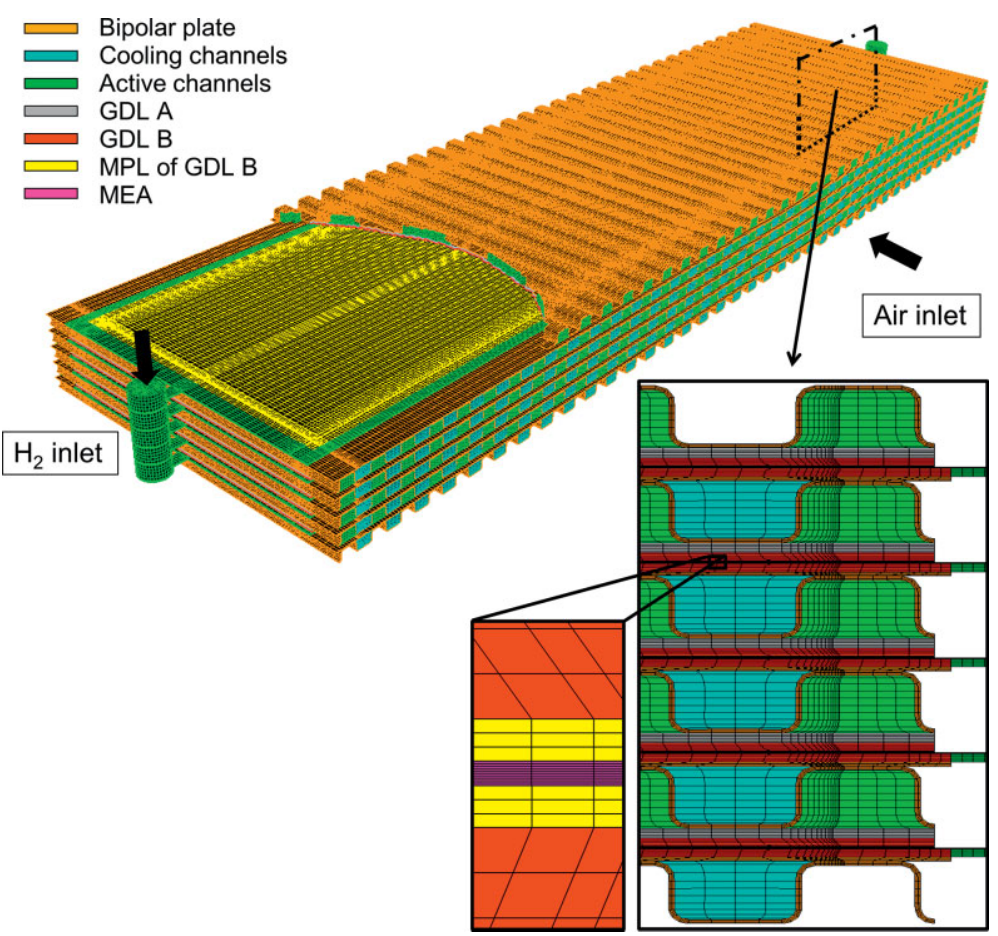

Fig. 2 Computational mesh of air-cooled 5-cell stack (geometry not to scale). 
Table 1 Material and transport parameters.

\begin{tabular}{|c|c|c|c|c|c|c|}
\hline Conductivity / porous media transport parameter & Symbol & GDL A & GDL B & MPL & Membrane & Bipolar plate \\
\hline Electronic conductivity / $\mathrm{S} \mathrm{m}^{-1}$ & $\sigma_{\text {ele }}$ & 3,931 & 1,312 & 1,312 & 0 & $1.35 \times 10^{6}$ \\
\hline Thermal conductivity / $\mathrm{W} \mathrm{m} \mathrm{m}^{-1} \mathrm{~K}^{-1}$ & $\lambda_{s}$ & 63.6 & 76.6 & 27.5 & 0.67 & 13.4 \\
\hline Porosity / - & $\varepsilon$ & 0.72 & 0.77 & 0.36 & 0.28 & - \\
\hline Permeability / $\mathrm{m}^{2}$ & K & $2.3 \times 10^{-13}$ & $2.6 \times 10^{-12}$ & $2.3 \times 10^{-14}$ & $1.8 \times 10^{-18}$ & - \\
\hline Membrane transport parameter & \multicolumn{2}{|c|}{ Reference value } & \multicolumn{2}{|c|}{ Activation energy / $\mathrm{J} \mathrm{mol}^{-1}$} & \multicolumn{2}{|c|}{ Reference temperature / K } \\
\hline Ionic conductivity / $\mathrm{S} \mathrm{m}^{-1}$ & $\sigma_{\text {ion,ref }}$ & 0.55 & $E_{a, \sigma}$ & 9,713 & $T_{r e f, \sigma}$ & 298.15 \\
\hline Water diffusion coefficient $/ \mathrm{m}^{2} \mathrm{~s}^{-1}$ & $D_{w, r e f}$ & $2.7 \times 10^{-11}$ & $E_{a, D}$ & 19,809 & $T_{r e f, D}$ & 298.15 \\
\hline Electro-osmotic drag coefficient / - & $C_{\text {drag,ref }}$ & 0.11 & $E_{a}, C_{\text {drag }}$ & 7,418 & $T_{r e f,} C_{d r a g}$ & 298.15 \\
\hline
\end{tabular}

Table 2 Boundary and operating conditions.

\begin{tabular}{|c|c|c|c|}
\hline \multirow[t]{5}{*}{ Cathode } & Inlet & Velocity / $\mathrm{m} \mathrm{s}^{-1}$ & $3.32 @ 0-3,500 \mathrm{~A} \mathrm{~m}^{-2}$, linear rise: $3.32 @ 3,500 \mathrm{~A} \mathrm{~m}^{-2}-8.4 @ 9,000 \mathrm{~A} \mathrm{~m}^{-2}$ \\
\hline & & Relative humidity / - & 0.29 \\
\hline & & Temperature / K & 295.15 \\
\hline & Outlet & Pressure / Pa & $1 \times 10^{5}$ \\
\hline & End plate & Electric potential / V & $2.94-5.085$ (stack voltage) \\
\hline \multirow[t]{5}{*}{ Anode } & Inlet & Pressure / Pa & $1.39 \times 10^{5}$ \\
\hline & & Relative humidity / - & 0 \\
\hline & & Temperature / K & 295.15 \\
\hline & Outlet & Pressure / Pa & Linear fall: $1.39 \times 10^{5} @ 200 \mathrm{~A} \mathrm{~m}^{-2}-1.37 \times 10^{5} @ 9,000 \mathrm{~A} \mathrm{~m}^{-2}$ \\
\hline & End plate & Electric potential / V & 0 \\
\hline \multirow[t]{2}{*}{ Remaining boundaries } & & Heat flux / $\mathrm{W} \mathrm{m}^{-2}$ & 0 \\
\hline & & Current density / $\mathrm{A} \mathrm{m}^{-2}$ & 0 \\
\hline Operating time / $\mathrm{h}$ & & & $0 @ 2.94 \mathrm{~V}-5.085 \mathrm{~V}$ (stack voltage), $500-7,000 @ 0.66 \mathrm{~V} \& 0.78 \mathrm{~V}$ (cell voltage) \\
\hline
\end{tabular}

Table 3 Kinetic parameters in basic model. Fitting parameter values are marked with an asterisk.

\begin{tabular}{llll} 
& Symbol & Cathode & Anode \\
\hline Reference exchange current density / A m ${ }^{-2}$ & $i_{0, \text { ref }}$ & $7.18 \mathrm{e}-5^{*}$ & $1,000^{*}$ \\
Reference temperature / K & $T_{r e f, i_{0}}$ & 353.15 & 353.15 \\
Activation energy / J mol ${ }^{-1}$ & $E_{a, i_{0}}$ & 66,000 & 0 \\
Anodic transfer coefficient / - & $k_{a}$ & 0.5 & 0.5 \\
Cathodic transfer coefficient / - & $k_{c}$ & $0.7^{*}$ & 0.5 \\
$\mathrm{O}_{2}$ exponent / - & $b_{\mathrm{O}_{2}}$ & $2^{*}$ & 0 \\
$\mathrm{H}_{2}$ exponent / - & $b_{\mathrm{H}_{2}}$ & 0 & 0.5 \\
$\mathrm{H}_{2} \mathrm{O}$ exponent / - & $b_{\mathrm{H}_{2} \mathrm{O}}$ & $0.1^{*}$ & 0
\end{tabular}

\subsection{Experimental Validation}

Figure 3 shows the polarization curve in simulation and experiment. The calculated curve is obtained from a fit to the measured curve with the fitting parameters from Table 3 . The agreement is excellent with a maximum deviation of $2 \%$. Also shown is the polarization curve with an IR-correction, i.e. without the ohmic contribution to the voltage loss. The high frequency resistance used to evaluate the ohmic loss was obtained by evaluating the impedance at $8 \mathrm{kHz}$. Also here, a maximum deviation between simulation and experiment of $2 \%$ can be achieved. Figure 3 further presents a comparison between calculated and measured average temperature in the catalyst layer vs. current density. The experimental data are measured using $\mathrm{S}^{++}$-sensor plates. In both simulation and experiment a strong temperature rise of about $40 \mathrm{~K}$ occurs in the current density range from 0 to $10,000 \mathrm{~A} \mathrm{~m}^{-2}$. The average temperature is predicted with a maximum error of $10 \%$.

Figure 4 shows the current density decay vs. operating time at cell voltages of $0.66 \mathrm{~V}$ and $0.78 \mathrm{~V}$. The calculated current densities are compared to through-life polarization measurements. For the sake of better visualization, the current density curves are divided by the values of the current density at a time of $0 \mathrm{~h}$. The trends of the performance decay are predicted correctly by the simulation: A steep current density drop in the first 1,000 hours is followed by an approximately linear part and a stronger decrease at the end of the fuel cell life. In order to understand these trends, changes of material parameters as a function of operating time have to be analyzed. Figure 5 shows membrane thickness, average ionic conductivity, average acid group concentration, and average cathode 


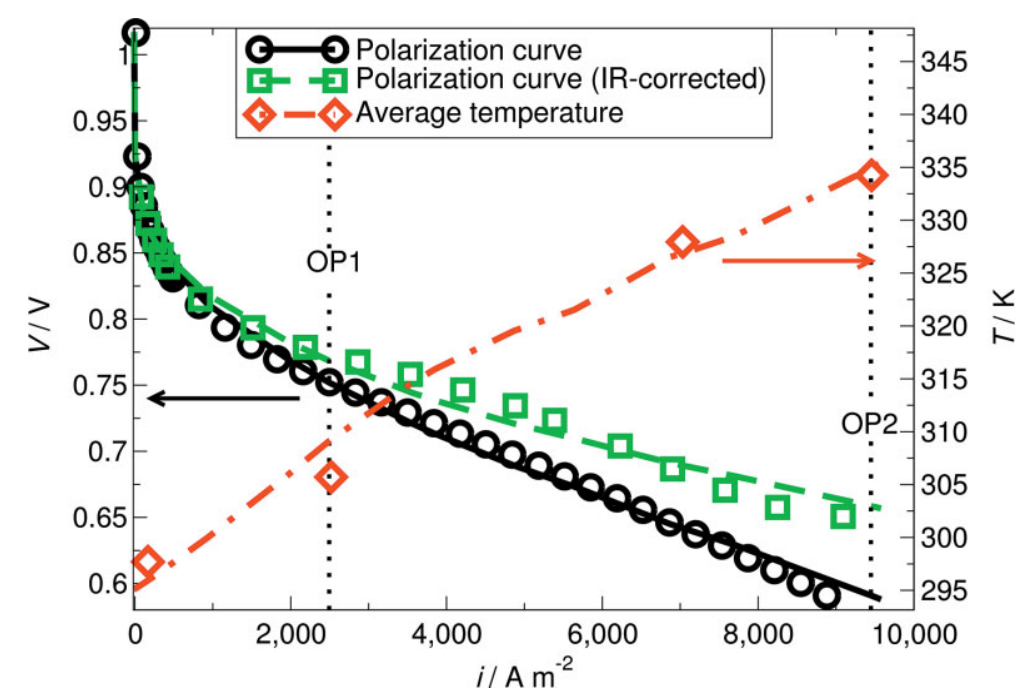

Fig. 3 Polarization curve, IR-corrected polarization curve, and average temperature vs. current density in simulation (lines) and experiment (symbols).

exchange current density vs. operating time normalized with the material parameter at operating time $0 \mathrm{~h}$. From these results can be concluded that

(i) the sudden initial current density drop is a consequence of catalyst layer degradation. Although the reference exchange current density in Eq. (49) depends only on the operating time, the value of the relative exchange current density calculated from Eq. (3) is slightly larger for the higher cell voltage. The reason for this behavior is the temperature dependency of the exchange current density in combination with the smaller temperature decay vs. operating time for higher voltages (less efficient cooling).

(ii) the stronger performance loss at $0.78 \mathrm{~V}$ compared to $0.66 \mathrm{~V}$ is caused by the change of the ionic conductivity due to membrane degradation in the first 1,000 hours. Mainly, the absolute value of the voltage itself is responsible for the stronger degradation at $0.78 \mathrm{~V}$ - see Eq. (47).

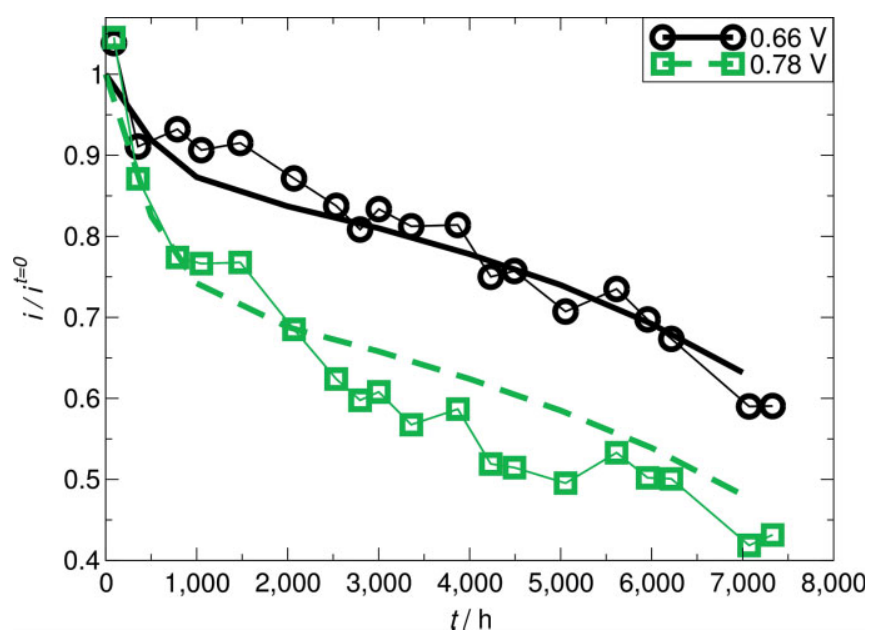

Fig. 4 Normalized current density vs. operating time for cell voltages of $0.66 \mathrm{~V}$ and $0.78 \mathrm{~V}$ in simulation (lines) and experiment (symbols).
As already pointed out in Section 2.2, the main focus of the developed degradation model is on the polymer electrolyte membrane rather than on the catalyst layer. Additionally, the catalyst layer is treated as an interface rather than a 3D domain as mentioned in Section 2.1. At the present time, it is not clear, how these two restrictions in the catalyst layer model affect the simulation results and, especially, the exchange current density vs. operating time shown in Figure 5. Currently ongoing modeling activities focus on this topic.

Now calculated current density and temperature distributions are compared to measurements obtained with $\mathrm{S}^{++}$-measurement plates [36] for two operating points: 2,494 $\mathrm{A} \mathrm{m}^{-2}$ (OP1) and 9,448 $\mathrm{A} \mathrm{m}^{-2}$ (OP2) - see vertical dotted lines in Figure 3. Figures 6 and 8 show the results in the form of color plots for OP1 and OP2, respectively. In Figures 7 and 9 results averaged in $\mathrm{H}_{2}$ - and air-flow direction are presented for both operating points. The simulation results are displayed in the spatial resolution of both the measurement plate and the computational mesh. In air-flow direction, current density and temperature distributions are qualitatively similar in simulation and experiment: Towards the air outlet the temperature increases and the current density decreases. Whereas calculated and measured current density gradients are in agreement, the temperature gradients in air-flow direction are underestimated by the simulation. The current density and temperature gradients in $\mathrm{H}_{2}$-flow direction are smaller than in air-flow direction. Here we see some differences between simulation and experiment: The current density has a convex shape in the simulation and a concave shape in the experiment. Approximately in the middle of the $\mathrm{H}_{2}$ flow path, a temperature maximum occurs in both simulation and experiment. However, again, calculated temperature gradients are smaller than in the experiment. Reasons for the deviations between simulation and experiment could be uncertainties in material parameters, especially of the porous GDLs and MPLs, or the fact that the number of segments of the measurement plates is far too small in order to catch the strongly varying current density differences in $\mathrm{H}_{2}$-flow direction (see simulation results at the resolution of the computational mesh).

\subsection{Interpretation of 3D Simulation Results}

\subsubsection{Healthy Stack}

Current density and temperature distributions in the resolution of the computational mesh have already been presented in Figures 6 and 8 bottom. Figures 10 and 11, additionally, show $\mathrm{H}_{2} / \mathrm{O}_{2}$ mole fractions in the catalyst layers and water concentration/water flux in the membrane, respectively. The 3D results obtained can be explained as follows:

(i) The current density decrease in air-flow direction (Figures 6 and 8 bottom left) can be attributed to the membrane water concentration decrease in this direction 


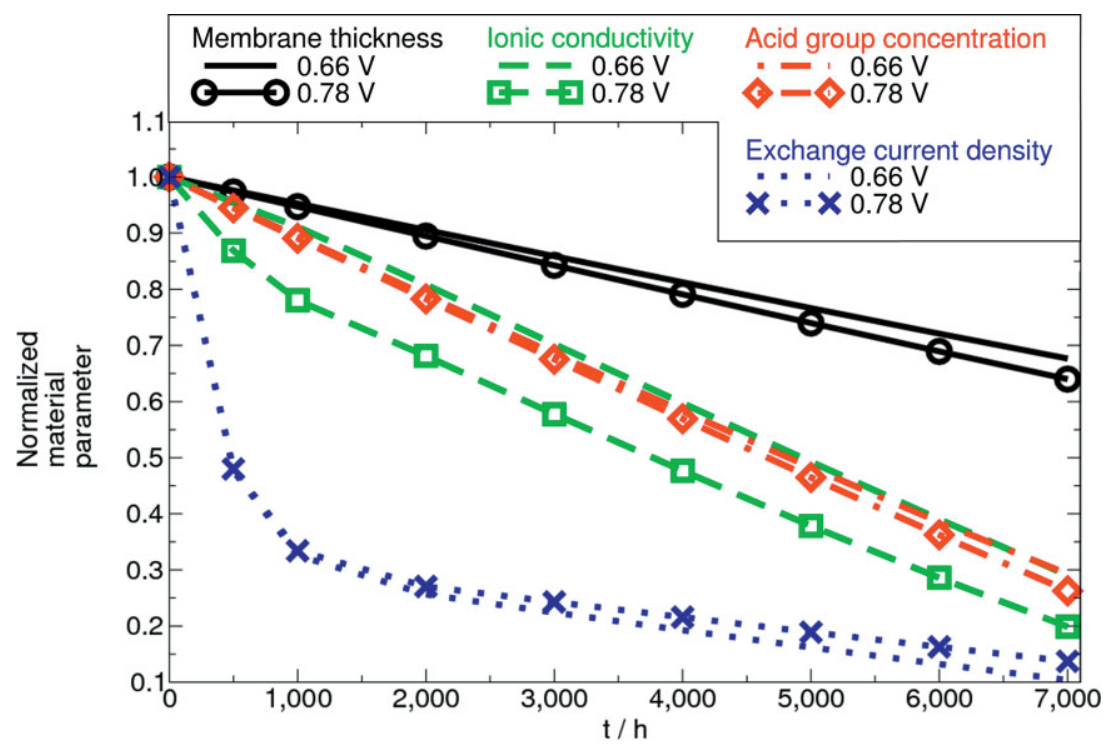

Fig. 5 Relative changes of membrane thickness, average ionic conductivity, average acid group concentration, and average cathode exchange current density vs. operating time for cell voltages of $0.66 \mathrm{~V}$ and $0.78 \mathrm{~V}$.

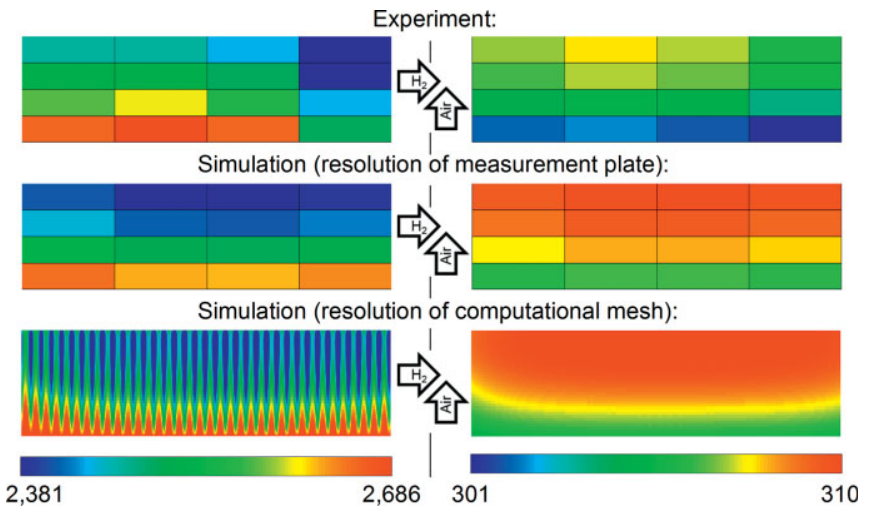

Fig. 6 Current density / $\mathrm{A} \mathrm{m}^{-2}$ (left) and temperature / $\mathrm{K}$ (right) in simulation (fine and coarse resolution) and experiment for OP1 (geometry not to scale).

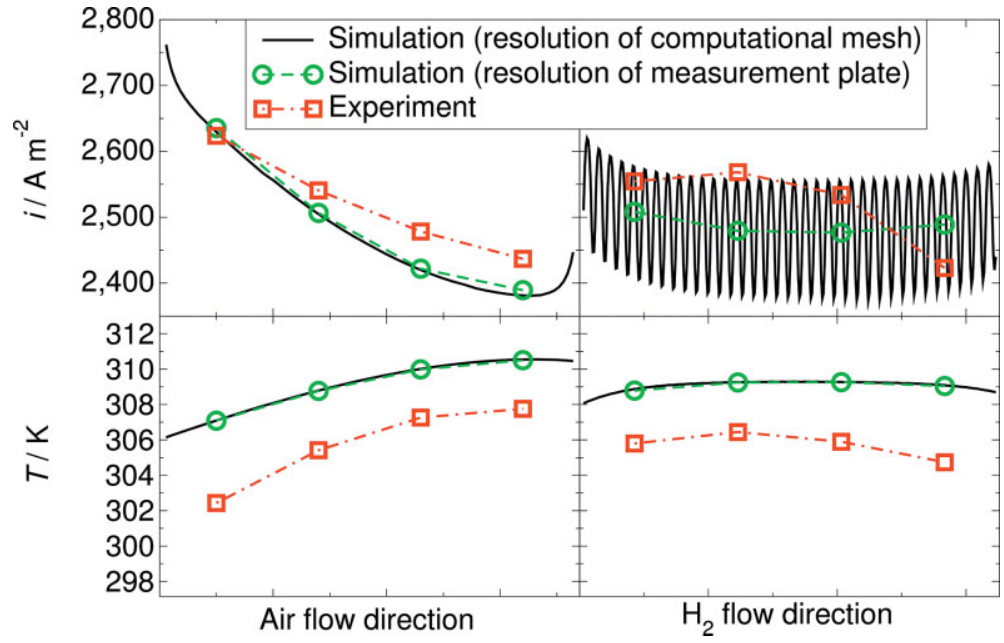

Fig. 7 Current density (top) and temperature (bottom) averaged in $\mathrm{H}_{2}$-flow direction (left) and air-flow direction (right) in simulation (fine and coarse resolution) and experiment for OPI.
(Figure 11 left) which, in turn, is caused by the temperature increase towards the air outlet (Figures 6 and 8 bottom right).

(ii) The current density below the air channels is higher than below the lands of the bipolar plate due to better oxygen access - see low $\mathrm{O}_{2}$ mol fraction below the lands in Figure 10 right.

(iii) The strong temperature gradient in air-flow direction is a consequence of using air as a coolant. The cooling performance of air is much worse than of liquids, mainly due to its lower heat capacity.

(iv) Figure 10 shows a stronger depletion of $\mathrm{O}_{2}$ than of $\mathrm{H}_{2}$ in the cathode and anode catalyst layers, respectively. Long diffusion paths through both cathodic GDLs and the fact that $\mathrm{O}_{2}$ has a smaller diffusion coefficient than $\mathrm{H}_{2}$ are the reasons for this behavior. On the anode side, $100 \% \mathrm{H}_{2}$ is transported parallel to the membrane from the channel across the GDL and MPL to the catalyst layer.

(v) The membrane water concentration below the air channels is lower than below the lands - see Figure 11 left. At this location the water vapor produced in the cathode catalyst layer can be transported more easily to the air channels than below the lands.

(vi) The higher current density below the air channels leads to water transport from the anode to the cathode via electro-osmotic drag - see positive values of membrane water flux in Figure 11 right. On the other hand, the higher water concentration below the lands causes back diffusion, i.e. a water transport from the cathode to the anode - see negative values of membrane water flux in Figure 11 right. 


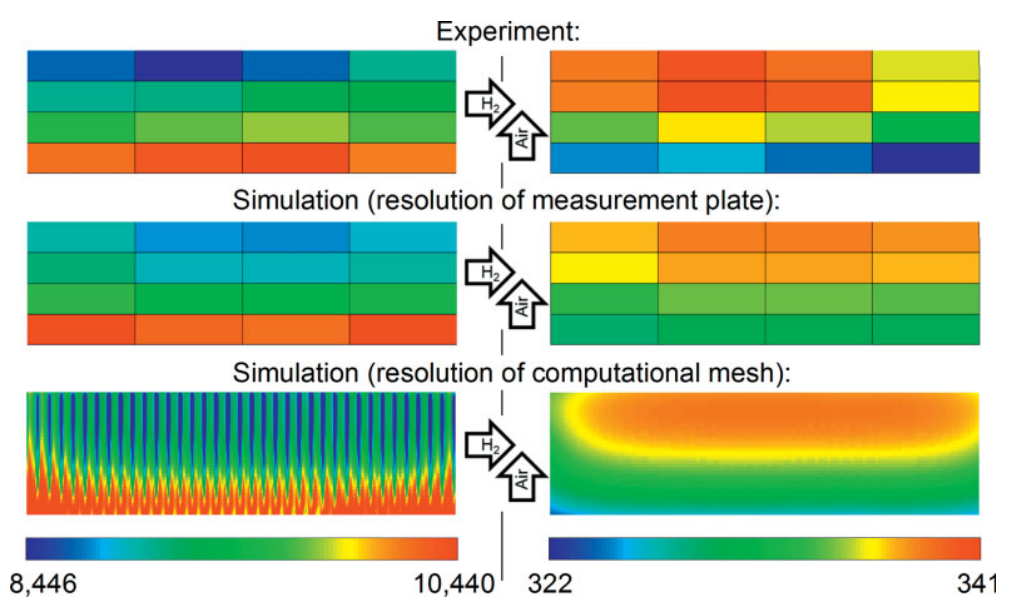

Fig. 8 Current density / $\mathrm{A} \mathrm{m}^{-2}$ (left) and temperature / $\mathrm{K}$ (right) in simulation (fine and coarse resolution) and experiment for OP2 (geometry not to scale).

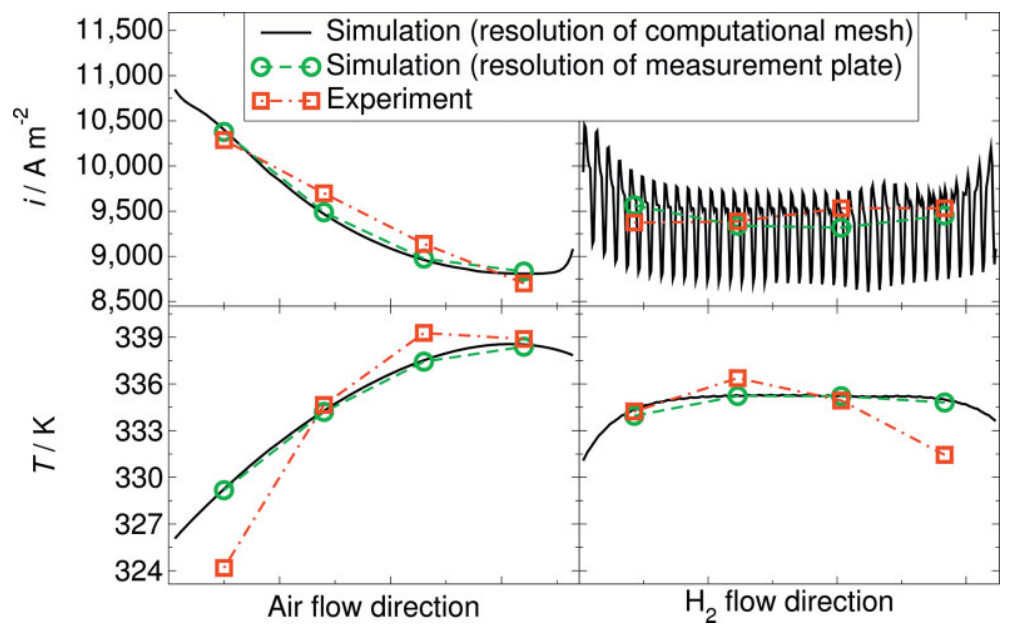

Fig. 9 Current density (top) and temperature (bottom) averaged in $\mathrm{H}_{2}$-flow direction (left) and air-flow direction (right) in simulation (fine and coarse resolution) and experiment for OP2.

(vii) The higher temperature for OP2 compared to OP1 leads to a considerably drier membrane for OP2. The gradients of all quantities in air-flow direction and between channel and land are more pronounced for OP2 than for OP1.

In Figure 12, temperature and flow lines of the whole stack are presented. The temperature increase towards the air outlet as well as cathode and anode gas flow directions can be identified.

\subsubsection{Degraded Stack}

Figures 13 and 14 show current density, ionic conductivity in a mid-plane of the membrane, and temperature at $0.66 \mathrm{~V}$ after operating times of $0 \mathrm{~h}$, 2,000 h, 4,000 h, and 6,000 h. Figure 13 shows the results in the form of color plots and in Figure 14 averages in $\mathrm{H}_{2}$ and air-flow direction are presented. The following observations can be made:

(i) The change of the local current density in airflow direction with proceeding operating time is mainly caused by the change of the ionic conductivity - see Figure 14a) and c): In air-flow direction the gradients for both quantities become smaller, i.e. their distributions become more homogeneous. Moreover, with proceeding operating time the maximum of the current density is shifted towards the air outlet due to the small value of the ionic conductivity at the air inlet.

(ii) As pointed out in the previous section, the current density difference between the regions below channel and land, i.e. current density maximum below channel and minimum below lands, is originating from the $\mathrm{O}_{2}$ depletion below the lands. In the first 4,000 operating hours the current density gradients between land and channel in $\mathrm{H}_{2}$-flow direction decrease - see Figure $14 b$ ) - due to less pronounced $\mathrm{O}_{2}$ depletion (smaller absolute value of current density). After about 4,000 hours the current density maximum begins shifting away from the region below the channel towards the region below the land (see also Figure 13 top) due to the strong decrease of the ionic conductivity below the channel - see Figure 14d) - leading to an increase of the current density gradients again. This means, after 4,000 hours the current density distribution is clearly determined by membrane degradation.

(iii) In air-flow direction the ionic conductivity gradient at the air inlet decreases with proceeding operating time - see

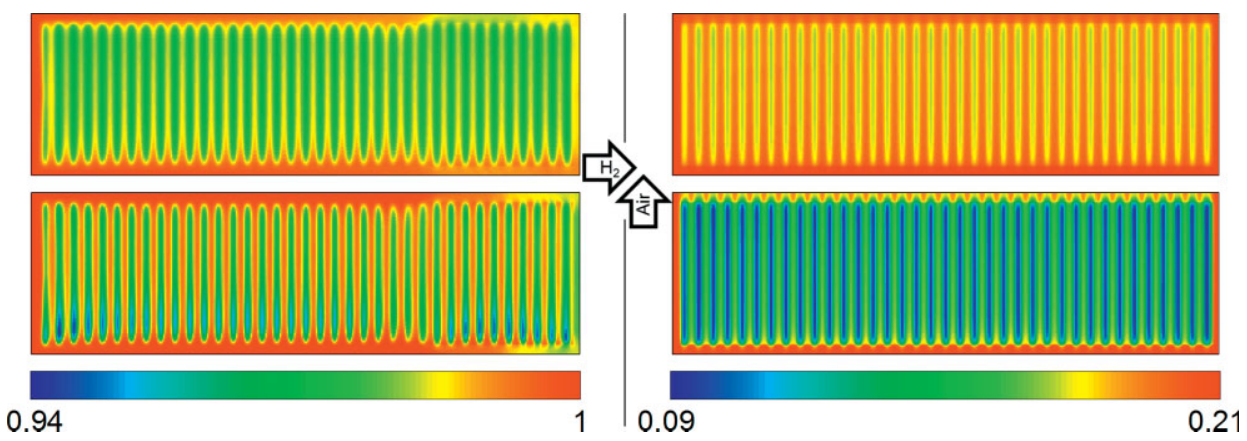

Fig. 10 Mole fractions of $\mathrm{H}_{2}$ (left) and $\mathrm{O}_{2}$ (right) in catalyst layers for OP1 (top) and OP2 (bottom). 


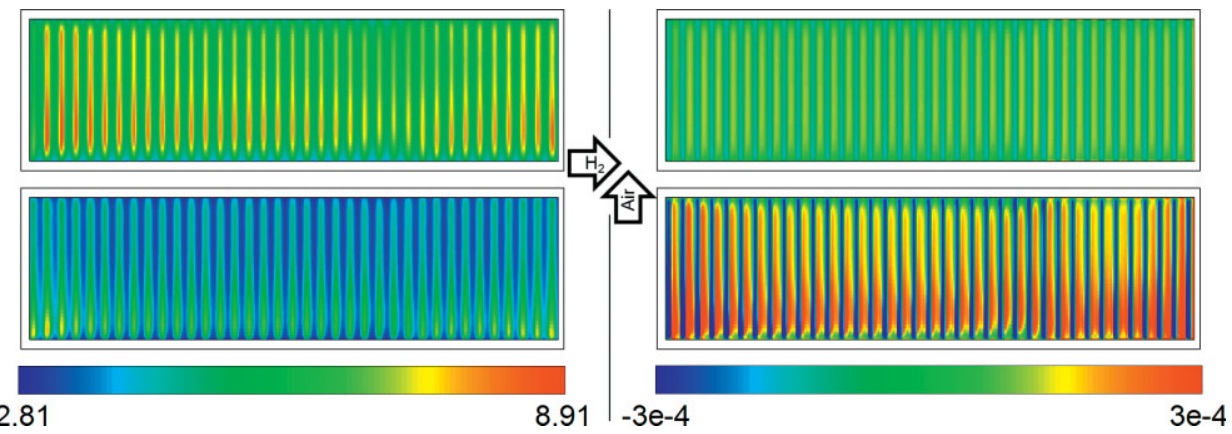

Fig. 11 Water concentration / - (left) and water flux component normal to the membrane $/ \mathrm{kg} \mathrm{m}^{-2} \mathrm{~s}^{-1}$ (right) in a mid-plane of the membrane for OP 1 (top) and OP2 (bottom).

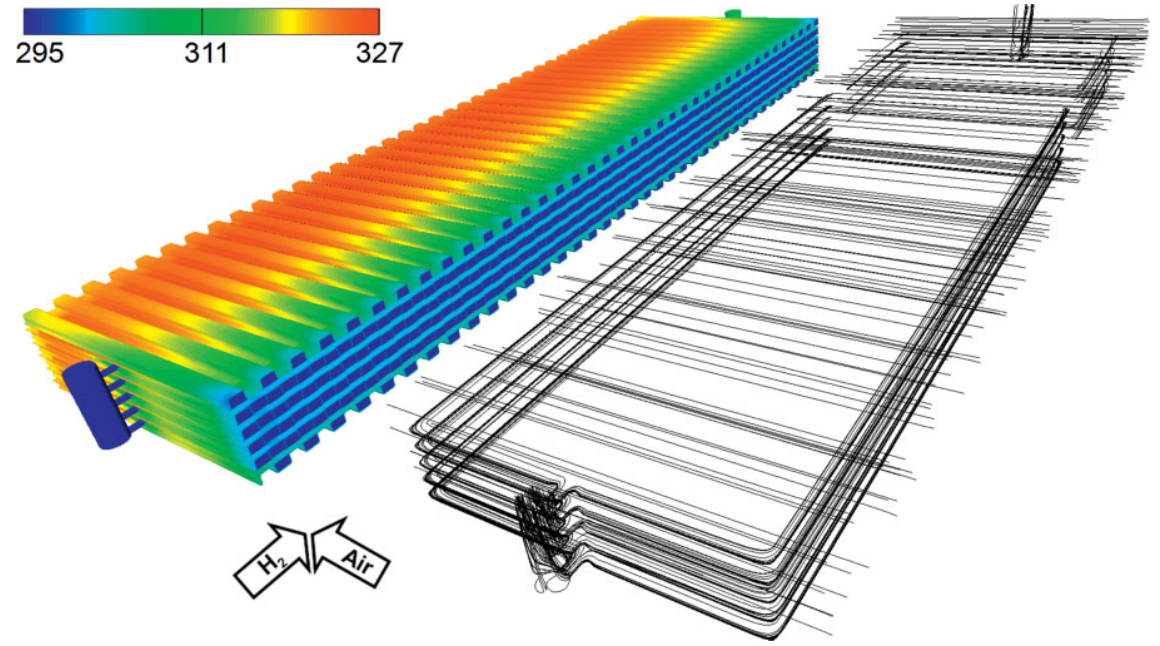

Fig. 12 Temperature / K (left) and flow lines (right) of whole stack at $0.66 \mathrm{~V}$ (geometry not to scale).

Figure 14c) - which is caused by the faster degradation of hotter locations - see Figure 14e) and Eq. (47).

(iv) Since the applied membrane degradation model is based on gas crossover effects and gas crossover is favored by higher relative humidity, more humid locations in the membrane lead to faster membrane degradation - see relative humidity influence in Eq. (47). The decrease of the conductivity gradient between land and air channel with proceeding operating time - see Figure 14d) - therefore can be explained as follows: The regions below the cathode lands are more humid than below the air channels and, hence, decrease faster leading to the observed gradient changes.

(v) The temperature distribution, shown in Figure 14e) and $\mathrm{f})$, is basically shifted vertically with proceeding operating time, i.e. a qualitative change in the temperature field due to degradation cannot be observed.

It must be noted here that the degradation model does not consider local catalyst layer degradation. Therefore, all the local current density changes due to degradation are attributed to membrane degradation, i.e. changes of the ionic conductivity due to chemical destruction of the polymer matrix. In reality local loss in cathode catalyst results in an increase in overpotential and, hence, higher thermodynamic losses, heat output and operating temperature. This in-turn increases the ohmic resistance of the membrane, which could then lead to local current density shifts. In such cases the membrane is not necessarily degraded - it is just unable to be operated at optimum conditions. These effects are addressed in a currently ongoing further development of the degradation model.

\section{Conclusions}

A comprehensive 3D PEM fuel cell model has been coupled with a semi-empirical degradation model in order to predict the performance loss as a function of operating time. The overall model has been validated against experimental data of an air-cooled PEM fuel cell stack. In the polarization curve and in the average temperature, maximum deviations between simulation and measurement of $2 \%$ and $10 \%$, respectively, could be achieved. The current density decay with proceeding operating time has been predicted with sufficient accuracy. The trends in current density and temperature distribution have been predicted correctly whereas the calculated temperature gradients were too small. With the help of 3D simulation results, a reasonable connection between current density, temperature, membrane water concentration, and oxygen concen- 


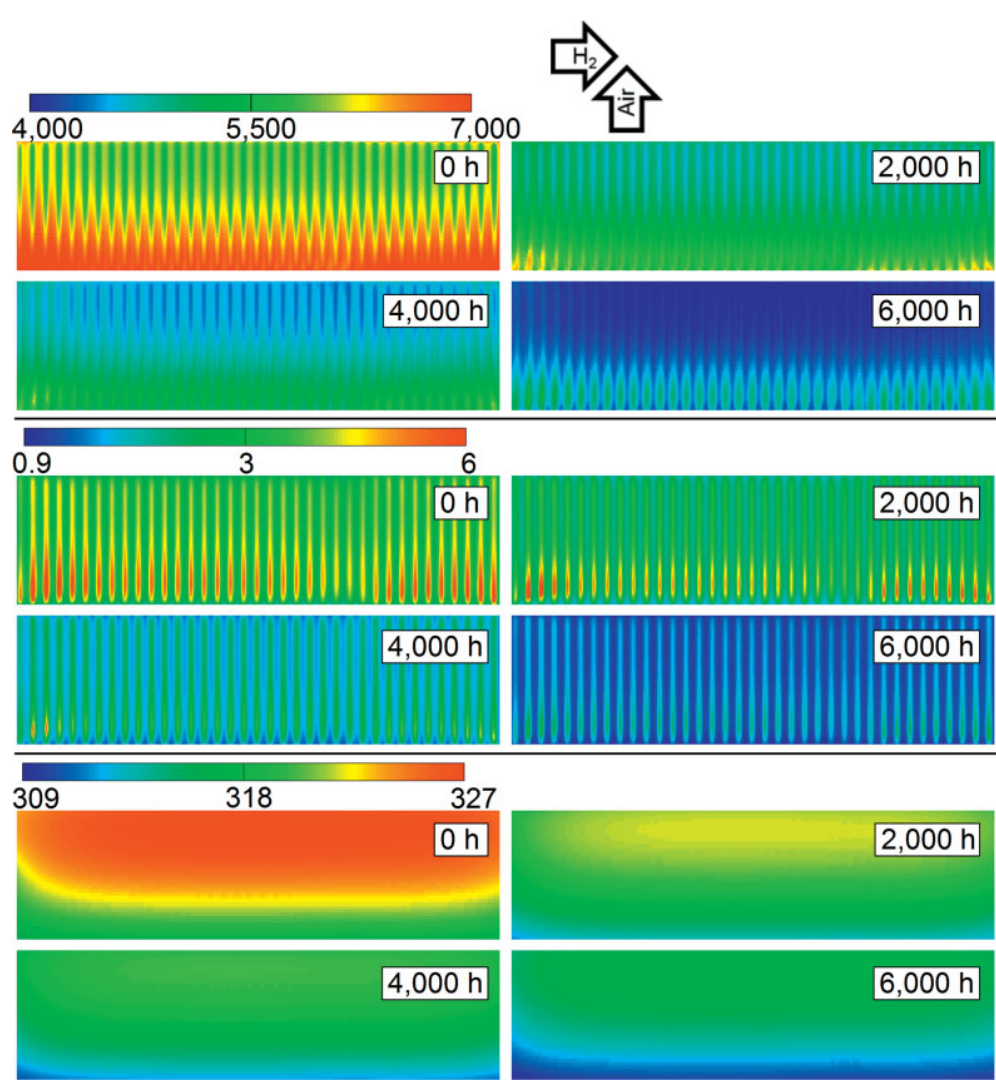

Fig. 13 Current density / $\mathrm{A} \mathrm{m}^{-2}$ (top), ionic conductivity $/ \mathrm{S} \mathrm{m}^{-1}$ (center), and temperature / $\mathrm{K}$ (bottom) at $0.66 \mathrm{~V}$ after $\mathrm{O} \mathrm{h}, 2,000 \mathrm{~h}, 4,000 \mathrm{~h}$, and 6,000 h (geometry not to scale).

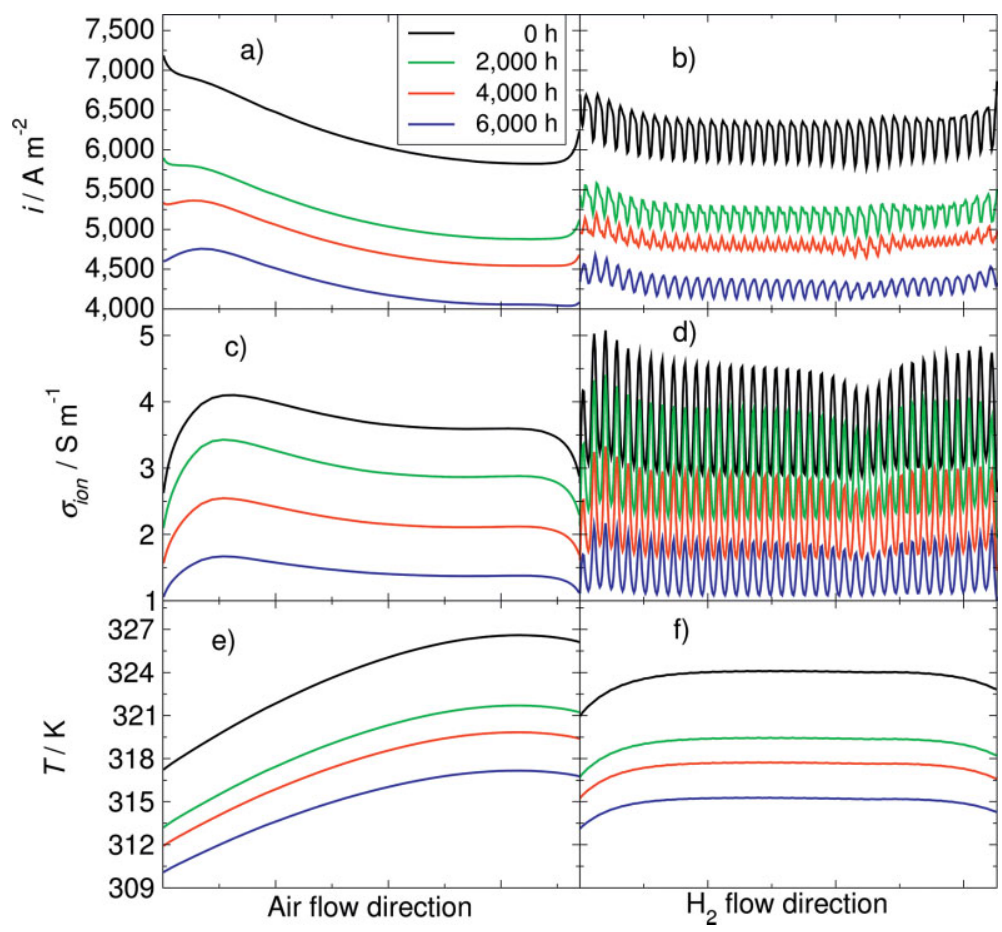

Fig. 14 Current density (top), ionic conductivity (center), and temperature (bottom) averaged in $\mathrm{H}_{2}$-flow direction (left) and air-flow direction (right) at $0.66 \mathrm{~V}$ after $\mathrm{O} \mathrm{h}$, $2,000 \mathrm{~h}, 4,000 \mathrm{~h}$, and $6,000 \mathrm{~h}$. tration could be established. In the investigation of $3 \mathrm{D}$ simulation results as a function of operating time, changes of the local current density could be attributed mainly to local changes of the ionic conductivity due to the destruction of the membrane polymer matrix. Since the degradation model presented in this paper is of empirical nature, it requires parameter fitting to a reference experiment. In future, the degradation model will be improved by replacing the empirical relations with chemically based equations with a focus on local catalyst layer degradation. Further development topics are a 3D description of the catalyst layers and an extension of the basic PEM fuel cell model to transient operating conditions.

\section{Acknowledgments}

The research leading to these results has received funding from the Austrian Research Promotion Agency (FFG), Project A3-FALCON, No. 835811.

\section{List of Symbols}

Latin letters

a Sulfonic acid group concentration $/ \mathrm{mol} \mathrm{m}^{-3}$

$b_{i} \quad$ Partial pressure exponent of gas species $i$ / -

$C_{\text {drag }} \quad$ Electro-osmotic drag coefficient / -

$C_{w} \quad$ Membrane water concentration divided by $a /$ -

$C_{w}^{*} \quad$ Membrane equilibrium sorption value of the water concentration / -

$D_{w} \quad$ Water diffusion coefficient in membrane $/ \mathrm{m}^{2} \mathrm{~s}^{-1}$

$E_{a} \quad$ Activation energy $/ \mathrm{J} \mathrm{mol}^{-1}$

$F \quad$ Faraday constant, $F=96,485 \mathrm{~A} \mathrm{~s} \mathrm{~mol}^{-1}$

$H \quad$ Specific total enthalpy $/ \mathrm{J} \mathrm{kg}^{-1}$

$\vec{i} \quad$ Current density / $\mathrm{A} \mathrm{m}^{-2}$

$i_{0} \quad$ Exchange current density $/ \mathrm{A} \mathrm{m}^{-2}$

$i_{r} \quad$ Reaction current density $/ \mathrm{A} \mathrm{m}^{-2}$

$\vec{j} \quad$ Diffusive mass flux $/ \mathrm{kg} \mathrm{m}^{-2} \mathrm{~s}^{-1}$

$\mathrm{J}_{\mathrm{O}_{2}} \quad$ Molar crossover flux of oxygen $/ \mathrm{mol} \mathrm{m}^{-2} \mathrm{~s}^{-1}$

$k_{a} \quad$ Anodic transfer coefficient / -

$k_{c} \quad$ Cathodic transfer coefficient / -

$\mathrm{K}$ Permeability tensor $/ \mathrm{m}^{2}$

$K_{p} \quad$ Hydraulic permeability of membrane $/ \mathrm{m}^{2}$

$L_{\text {mem }} \quad$ Membrane thickness / $\mathrm{m}$

$\overrightarrow{\dot{m}} \quad$ Mass flux $/ \mathrm{kg} \mathrm{m}^{-2} \mathrm{~s}^{-1}$

$M \quad$ Molar mass $/ \mathrm{kg} \mathrm{mol}^{-1}$

$\dot{M}_{p c} \quad$ Mass transfer rate from phase change $/ \mathrm{kg} \mathrm{m}^{-3} \mathrm{~s}^{-1}$ 
$\vec{n} \quad$ Unit normal vector pointing towards the membrane / -

$\overrightarrow{\dot{n}}_{w} \quad$ Molar membrane water flux $/ \mathrm{mol} \mathrm{m}^{-2} \mathrm{~s}^{-1}$

$p \quad$ Pressure / Pa

$p_{i} \quad$ Partial pressure of gas species $i / \mathrm{Pa}$

$\dot{q} \quad$ Heat flux $/ \mathrm{W} \mathrm{m}^{-2}$

$\dot{Q}_{D} \quad$ Volumetric heat transfer rate from gas species diffusion / $\mathrm{W} \mathrm{m}^{-3}$

$\dot{Q} \quad$ Volumetric heat transfer rate / $\mathrm{W} \mathrm{m}^{-3}$

$\dot{Q}_{p c} \quad$ Volumetric heat transfer rate from phase change $/ \mathrm{W} \mathrm{m}^{-3}$

$\dot{r}_{\psi} \quad$ Degradation rate for quantity $\psi / \mathrm{h}^{-1}$

$R \quad$ Universal gas constant, $R=8.314 \mathrm{~J} \mathrm{~mol}^{-1} \mathrm{~K}^{-1}$

$\vec{S} \quad$ Volumetric momentum transfer force / $\mathrm{N} \mathrm{m}^{-3}$

$\vec{S}_{p c} \quad$ Momentum source from phase change $/ \mathrm{N} \mathrm{m}^{-3}$

$t \quad$ Operating time $/ \mathrm{h}$

T Temperature / $\mathrm{K}$

$\vec{u} \quad$ Velocity / $\mathrm{m} \mathrm{s}^{-1}$

$V \quad$ Cell voltage / V

y Gas species mass fraction / -

\section{Greek letters}

$\alpha \quad$ Volume fraction / -

$\gamma_{w} \quad$ Mass transfer coefficient $/ \mathrm{m} \mathrm{s}^{-1}$

$\varepsilon \quad$ Porosity / -

$\eta \quad$ Activation overpotential / V

$\lambda \quad$ Thermal conductivity / $\mathrm{W} \mathrm{m}^{-1} \mathrm{~K}^{-1}$

$\lambda \quad$ Thermal conductivity tensor $/ \mathrm{W} \mathrm{m}{ }^{-1} \mathrm{~K}^{-1}$

$\mu_{w} \quad$ Water dynamic viscosity in membrane / Pa s

$\rho \quad$ Density $/ \mathrm{kg} \mathrm{m}^{-3}$

$\sigma \quad$ Electrical conductivity $/ \mathrm{S} \mathrm{m}^{-1}$

$\sigma \quad$ Electrical conductivity tensor $/ \mathrm{S} \mathrm{m}^{-1}$

$\tau \quad$ Tortuosity / -

$\tau \quad$ Shear stress tensor $/ \mathrm{N} \mathrm{m}^{-1}$

$\phi \quad$ Electric potential / V

$\phi_{o c} \quad$ Open circuit potential / V

$\varphi_{w} \quad$ Relative humidity / -

\section{Superscripts}

$f \quad$ Interface membrane / catalyst layer

$t \quad$ Value after operating time $t$

\begin{tabular}{ll}
\multicolumn{2}{l}{ Subscripts } \\
ano & Anode catalyst layer \\
cat & Cathode catalyst layer \\
ele & Electronic phase \\
$g$ & Gaseous phase \\
$i$ & Gas species index \\
ion & Ionic phase \\
$l$ & Liquid phase \\
$m e m$ & Membrane \\
$p$ & Phase index \\
$r e f$ & Reference value \\
$s$ & Solid phase
\end{tabular}

Abbreviations

CFD Computational Fluid Dynamics

CPU Central Processing Unit

GDL Gas Diffusion Layer

MEA Membrane Electrode Assembly

MPL Microporous Layer

OP Operating Point

PEM Polymer Electrolyte Membrane

REV Representative Elementary Volume

\section{References}

[1] E. Hontañón, M. J. Escudero, C. Bautista, P. L. GarcíaYbarra, L. Daza, J. Power Sources 2000, 86, 363.

[2] N. Ahmadi, S. Rezazadeh, I. Mirzaee, N. Pourmahmoud, J. Mech. Sci. Technol. 2012, 26, 2247.

[3] A. Iranzo, F. Rosa, J. Pino, Energies 2009, 2, 582.

[4] A. Kumar, R. G. Reddy, J. Power Sources 2003, 114, 54.

[5] S. M. Baek, S. H. Yu, J. H. Nam, C.-J. Kim, Appl. Therm. Eng. 2011, 31, 1427.

[6] E. Özden, I. Tolj, F. Barbir, Appl. Therm. Eng. 2013, 51, 1339.

[7] M. Bosomoiu, G. Tsotridis, T. Bednarek, J. Power Sources 2015, 285, 568.

[8] L. Karpenko-Jereb, C. Sternig, C. Fink, V. Hacker, A. Theiler, R. Tatschl, J. Power Sources 2015, 297, 329.

[9] A. Verma, R. Pitchumani, J. Power Sources 2014, 268, 733.

[10] S. Strahl, A. Husar, A. A. Franco, Int. J. Hydrogen Energ. 2014, 39, 9752.

[11] S. Shimpalee, U. Beuscher, J. W. Van Zee, J. Power Sources 2006, 163, 480.

[12] Y. Shan, S.-Y. Choe, J. Power Sources 2006, 158, 274.

[13] D. H. Jeon, K. N. Kim, S. M. Baek, J. H. Nam, Int. J. Hydrogen Energ. 2011, 36, 12499.

[14] C. Y. Jung, W. J. Kim, S. C. Yi, Int. J. Hydrogen Energ. 2012, 37, 7654 .

[15] A. Atifi, A. El-Marjani, H. Mounir, International Review on Modeling and Simulations 2014, 7, 945.

[16] M. A. R. Sadiq Al-Baghdadi, Recent Patents on Mechanical Engineering 2009, 2, 26.

[17] A. A. Franco, in Polymer Electrolyte Membrane and Direct Methanol Fuel Cell Technology (Eds. C. Hartnig, C. Roth), Woodhead Publishing, 2012, pp. 291.

[18] A. A. Franco, M. Tembely, J. Electrochem. Soc. 2007, 154, B712.

[19] A. A. Franco, M. Guinard, B. Barthe, O. Lemaire, Electrochim. Acta 2009, 54, 5267.

[20] K. Malek, A. A. Franco, J. Phys. Chem. B 2011, 115, 8088.

[21] C. Robin, M. Gerard, A. A. Franco, P. Schott, Int. J. Hydrogen Energ. 2013, 38, 4675.

[22] E. Ozden, I. Tari, J. Power Sources 2016, 304, 64.

[23] FIRE $^{\circledR}$ v2014, Electrification/Hybridization Manual, AVL List GmbH, 2014.

[24] M. Kaviany, Principles of Heat Transfer in Porous Media, Springer New York, 1991, pp. 53. 
[25] L. Karpenko-Jereb, P. Innerwinkler, A.-M. Kelterer, C. Sternig, C. Fink, P. Prenninger, R. Tatschl, Int. J. Hydrogen Energ. 2014, 39, 7077.

[26] C. Fink, N. Fouquet, Electrochim. Acta 2011, 56, 10820.

[27] K. H. Wong, E. Kjeang, J. Electrochem. Soc. 2014, 161, F823.

[28] C. Lim, L. Ghassemzadeh, F. V. Hove, M. Lauritzen, J. Kolodziej, G. Wang, S. Holdcroft, E. Kjeang, J. Power Sources 2014, 257, 102.

[29] L. Ghassemzadeh, S. Holdcroft, J. Am. Chem. Soc. 2013, 135,8181 .

[30] A. A. Shah, T. R. Ralph, F. C. Walsha, J. Electrochem. Soc. 2009, 156, B465.
[31] X.-Z. Yuan, S. Zhang, S. Ban, C. Huang, H. Wang, V. Singara, M. Fowler, M. Schulze, A. Haug, K. A. Friedrich, R. Hiesgen, J. Power Sources 2012, 205, 324.

[32] L. Karpenko-Jereb, C. Sternig, C. Fink, R. Tatschl, Int. J. Hydrogen Energ. 2016, submitted.

[33] K. D. Baik, B. K. Hong, M. S. Kim, Renew. Energ. 2013, 57, 234.

[34] P. J. Ferreira, G. J. la O', Y. Shao-Horn, D. Morgan, R. Makharia, S. Kocha, H. A. Gasteiger, J. Electrochem. Soc. 2005, 152, A2256.

[35] Z.-B. Wang, P.-J. Zuo, X.-P. Wang, J. Lou, B.-Q. Yang, G.-P. Yin, J. Power Sources 2008, 184, 245.

[36] S++ Simulation Services, can be found under http:// www.splusplus.com, 2015. 